\title{
Medical Benefits of Using Natural Compounds and Their Derivatives Having Multiple Pharmacological Actions
}

\author{
Ikuko KIMURA \\ Department of Clinical Pharmacology, Graduate School of Pharmaceutical Sciences, Toyama Medical and \\ Pharmaceutical University, 2630 Sugitani, Toyama 930-0194, Japan
}

(Received December 19, 2005)

\begin{abstract}
The multiple pharmacological actions of a unique compound are a prerequisite for classifying drugs as highly efficacious, because the multiple pharmacological actions offer the possibility of treating various symptoms of chronic diseases as described below. 1) Sustained hyperglycemia induces macrovascular and microvascular complications in type 2 diabetes mellitus. Antihyperglycemic medication and the control of postprandial hyperglycemia are essentially important for normalizing plasma glucose level. Gymnemic acid IV isolated from Gymnema sylvestre (Asclepiadaceae) leaves has antisweet, antihyperglycemic, glucose uptake inhibitory, and gut glycosidase inhibitory effects. Most of these pharmacological effects may synergistically contribute to alleviating type 2 diabetes-related symptoms. 2) Diabetic skeletal and vascular smooth muscles are hypersensitive to chemical transmitters, cytokines and autacoids. The sensitivity of neuromuscular synapses is enhanced in diabetes, which seems to be closely associated with neuropathy as one of the diabetic complications. $\beta$-Eudesmol found in Atractylodes lancea rhizome has a desensitizing channel blocking action to nicotinic acetylcholine receptors, anti-angiogenic action in vascular endothelium, and neuronal differentiation actions. These multiple pharmacological actions are favorable for treating angiogenic diseases possibly including the complications of diabetes, namely, retinopathy and nephropathy, and cancer. 3) Nipradilol is clinically utilized as a topical antiglaucoma drug. The ocular hypotensive effects of this compound are brought about by its $\alpha_{1}$ - and $\beta$-adrenergic receptor blocking actions, and nitric oxide (NO) releasing action. NO directly activates cyclooxygenases. All these pharmacologic effects are beneficial for treating glaucoma. The selectivity and specificity of drug action are required for treating acute diseases, infections or for acting as useful reagents. The pleiotropic actions of natural compounds and their derivatives serve as important clues for developing new drugs for various chronic diseases.
\end{abstract}

Key words_— multidirectional pharmacological actions; powerful drugs; gymnemic acid IV; $\beta$-eudesmol; nipradilol

\section{INTRODUCTION}

After serendipitous biological findings had been made, certain prototypic structures were further derivatized to obtain compounds with improved or efficacious novel pharmacologic effects. Selectivity and specificity have been considered to be prerequisites for considering compounds as beneficial drugs such as antibiotics for acute infections or for finding useful reagents in research. However, it is not very important for clinicians to prescribe certain medicines for chronic diseases because these medicines often cause severe side effects due to their specificity in vivo. There are many cases wherein natural products and

Present address: Department of Food and Nutrition Science, Toyama College, 444 Gankaiji, Toyama 9300193, Japan

e-mail: ikukokim@pa.ctt.ne.jp

This review article is published on the occasion of retirement from the university in March 2005. synthetic compounds by themselves exert multiple pharmacological actions. These pharmacological multiactions become practical prerequisites for identifying highly efficacious drugs with multiple pharmacological actions for the simultaneous treatment of multifactorial symptoms of chronic diseases. In this study, an antihyperglycemic drug, an antiangiogenic drug, and an antiglaucoma drug having pleiotropic actions will be discussed as therapeutic compounds.

\section{MULTIDIRECTIONAL ANTIHYPERGLYCEMIC ACTIONS OF GYMNEMIC ACID IV}

Over the last few decades, there has been an exponential increase in the prevalence of type 2 diabetes worldwide, with estimates suggesting that 200 million people now suffer from the condition. Type 2 diabetes mellitus is a chronic metabolic disorder caused by insulin deficiency or insulin resistance. Sustained hyperglycemia induces macrovascular (mostly atherosclerosis) and microvascular complications (retinopathy, 
nephropathy and neuropathy). Nonenzymatic products of glucose (called advanced glycation endproducts, or AGE) have been implicated in the development of these complications. Normalizing plasma glucose level is associated with the prevention and alleviation of diabetic complications. Antihyperglycemic medication and the control of postprandial hyperglycemia are essentially important for normalizing plasma glucose level.

Inhibiting intestinal glucose absorption and hepatic glucose output, increasing glucose uptake in striated muscles, and stimulating insulin secretion unless patients suffer from insulin resistance, are methods for preventing diabetes. From traditional Kampo medicines to herbs and foodstuffs, we have also screened candidate crude drugs and constituent compounds with antihyperglycemic effects in type 2 diabetic model rodents, and in healthy human volunteers with improvement of oral glucose tolerance. The natural compounds investigated were categorized as follows. 1) Compounds that stimulate insulin secretion: non-saponin fraction of ginseng root (Panax spp., Araliaceae) , ,2) fagomine, a $N$-containing sugar derived from mulberry leaves (Morus spp., Moraceae.) ${ }^{3-5)}$ and gymnemic acid IV (Fig. 1(A))

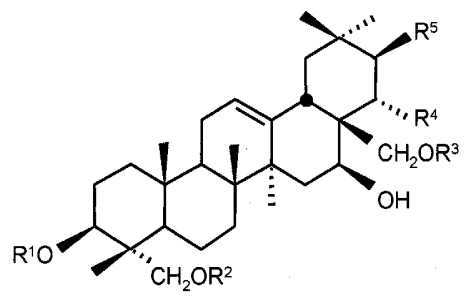

\begin{tabular}{lccccc} 
& $\mathrm{R}^{1}$ & $\mathrm{R}^{2}$ & $\mathrm{R}^{3}$ & $\mathrm{R}^{4}$ & $\mathrm{R}^{5}$ \\
\hline \hline Gymnemic acid I & GlcA & $\mathrm{H}$ & $\mathrm{Ac}$ & OH O-Tig \\
Gymnemic acid II & GlcA & H & Ac & OH O-MB \\
Gymnemic acid III & GlcA & H & H & OH O-MB \\
Gymnemic acid IV & GlcA & H & H & OH O-Tig \\
Gymnemasaponin V & H & Glc6-Glc & Glc6-Glc & H & H \\
\hline
\end{tabular}

Tig: tigloyl, MB: (2S) -methylbutyroyl, GlcA: $\beta$-D-glucopyranosyl

Fig. 1(A). Chemical Structures of Gymnemic Acid I, II, III and IV, and Gymnemasaponin V derived from Gymnema sylvestre (Asclepiadaceae) leaves, ${ }^{6}$ 2) Compounds that inhibit intestinal glucose absorption (glycosidase inhibition): gymnemic acid IV, 3) Compounds that increase glucose uptake in striated muscles: mulberry leaf extract, ${ }^{7)}$ 4) Compounds that inhibit the sweet taste (antisweet effect): gymnemic acid IV,8) 5) Compounds with other mechanisms not associated with insulin release: pseudoproto-timosaponin-AIII derived from rhizomes of Anemarrhena asphodeloides (Liliaceae), ${ }^{9)}$ and green tea (Camellia sinensis, Theaceae), ${ }^{10)}$ and with unidentified mechanisms: isofumulones from flower cone with lupulin of hops (Humulus lupulus L., Moraceae). ${ }^{11)}$ Some of these natural products are contained in traditional medicines composed of various compounds, such as "byakkokaninjinto" (composed of the rhizome of Anemarrhena asphodeloides, ginseng root, licorice root, rice grain, and fibrosum gypsum). ${ }^{12}$ The decisive selection and use of these natural compounds depend on the disease state of prediabetic or diabetic patients to prevent the aggravation of the disease.

Gymnemic acid IV mentioned above is a multidirectional (Table 1) antihyperglycemic agent which has 1) antisweet taste, ${ }^{8)}$ 2) blood-glucose

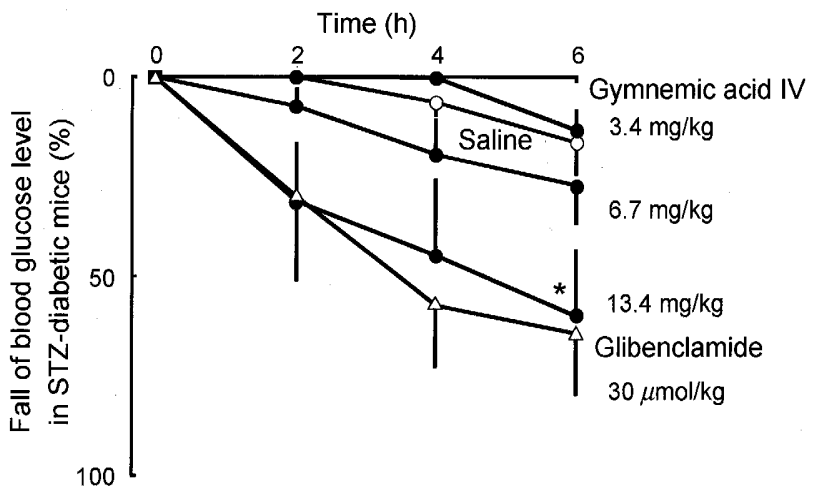

Fig. 1(B). Time-dependent Blood-glucose Lowering Effect of Gymnemic Acid IV (O: 3.4, 6.7 and $13.4 \mathrm{mg} / \mathrm{kg}, i . p ., n$ $=5)$ Compared with that of Glibenclamide $(\triangle: 14.8 \mathrm{mg} / \mathrm{kg}$ $(30 \mu \mathrm{mol} / \mathrm{kg})$, i.p., $n=5)$ in Streptozotocin-diabetic Mice ${ }^{6}$ The values are expressed as mean (\%) \pm S.E.M. ${ }^{*} p<0.05$ : Significant difference from saline control $(O: n=4)$. (Reprinted from Sugihara et al., 2000 , with permission from JANPR) 6

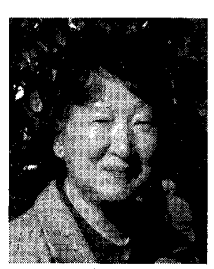

Ikuko Kimura
Adjunct Prof., Dept. of Food and Nutrition Science, Toyama College. Born in 1939 in Toyama. B.Sc.: University of Toyama (1962), M.Sc.: Kyoto University, Graduate School of Engineering (1970). Ph.D.: University of Tokyo (1973) . Prof., Dept. of Clinical Pharmacology, Graduate School of Pharm. Sci., Toyama Medical and Pharmaceutical University (2000-2005). Prizes and Awards: The Miyata Prize (1989) and the PSJ Award for Divisional Scientific Research Contributions (1998) from the PSJ. Sci. Soc.: a member of the board of directors in Med. and Pharm. Soc. for WAKAN-YAKU (2002-2006) . Major Research Interest: Evidence-based pharmacology of traditional medicines. 
Table 1. Glucose Metabolism-related Effects by Gymnemic Acids I, II, III, IV and Gymnemasaponin V

\begin{tabular}{lcccc}
\hline \hline & $\begin{array}{c}\text { Antihyper- } \\
\text { glycemia }\end{array}$ & $\begin{array}{c}\text { Glucose uptake } \\
\text { inhibition }\end{array}$ & $\begin{array}{c}\alpha \text {-Glycosidase } \\
\text { inhibition }\end{array}$ & Antisweet \\
\hline Gymnemic acid I & - & - & & 0 \\
Gymnemic acid II & - & 0 & - & 0 \\
Gymnemic acid III & - & - & 0 \\
Gymnemic acid IV & - & 0 & & 0 \\
Gymnemasaponin V & - & - & & \\
\hline
\end{tabular}

: effective, - : no effect, vacant column : not tested.

(Reprinted from Sugihara et al., 2000, with permission from JANPR) .6)

lowering (Fig. 1(B)), 6) 3) glucose uptake inhibitory, and 4) gut glycosidase inhibitory (Table 1) actions. ${ }^{7)}$ Most of these pharmacological actions may beneficially contribute to alleviating type 2 diabetes-related symptoms. Thus, gymnemic acid IV may be used as a prophylactic against diabetes through its different mechanisms of action.

\section{MULTIDIRECTIONAL ACTIONS OF $\beta$-EUDESMOL}

Microangiopathy (retinopathy, nephropathy and neuropathy) develops as a consequence of sustained hyperglycemia. The skeletal and vascular smooth muscles are hypersensitive to chemical transmitters, cytokines and autacoids in diabetic state; this hypersensitivity is attributed to the up-regulation of their receptors caused by a deficiency in the amounts of the endogenous mediators. Traditional medicines are frequently used to improve diabetic complications. We have clarified the mechanisms underlying the drug actions in neuromuscular synapses and blood vessels of diabetic rodents. The sensitivity of neuromuscular synapses is enhanced in the diabetic state, and the inhibition of neuromuscular synapses by suxamethonium, a depolarizing and desensitizing neuromuscular blocker, is enhanced in the disease state. Similarly, the neuromuscular blockade caused by a traditional prescription of a combination of crude drugs "keishikajutsubuto", mainly consisting of peony root, licorice root, Atractylodes lancea rhizome and aconite root, is enhanced in the diabetic state. ${ }^{13)}$

$\beta$-Eudesmol, a sesquiterpenoid alcohol derived from $A$. lancea rhizomes, enhances the neuromuscular blocking action of suxamethonium ${ }^{14)}$ by inducing nicotinic acetylcholine receptor (nAChR) desensitization $^{15)}$ and its neuromuscular blocking effect is exerted more in diabetic mice than in normal mice. ${ }^{13)} \beta$ -
Eudesmol alone depresses nerve-evoked twitch tension, decreases the amplitude of acetylcholine potential, and reduces the amplitude and quantal size of endplate potential, but it does not alter quantal content, resting membrane potential and action potential. ${ }^{16}$ This compound accelerates the slow decay of depolarization, and decreases both open time and opening frequency without affecting single-channel conductance, suggesting a mixed type nAChR-channel blocking effect (Table 2) (open-channel blocking and closed-channel blocking effects) ${ }^{17,18)}$ This blocking effect occurs at lower concentrations of $\beta$-eudesmol than those of bupivacaine, an open-channel blocker. The compound shortens the duration of nAChR activity-modulating noncontractile intracellular $\mathrm{Ca}^{2+}$ (RAMIC) ${ }^{19)}$ in isolated skeletal muscle endplates, and it enhances the suxamethonium-induced inhibition of contractile $\mathrm{Ca}^{2+}$ transients in isolated skeletal muscles of mice. ${ }^{18)}$

We previously reported that an extract of $A$. lancea rhizomes, containing the bioactive compound $\beta$ eudesmol, inhibits the angiogenesis of adjuvant-induced air pouch granuloma in mice, an in vivo model of chronic inflammation. ${ }^{20)}$ The degree of angiogenesis in vivo was determined in adjuvant-induced granuloma in mice by measuring carmine content. The intraperitoneal injection of $\beta$-eudesmol induced a marked reduction in angiogenesis than that of hydrocortisone (Table 3).21) $\beta$-Eudesmol inhibits tube formation (angiogenesis) of endothelial cells in the rat aorta (unpublished data). The antiangiogenic effect of $\beta$-eudesmol is greater than that of hydrocortisone (Fig. 2(A)). The proliferation of porcine brain microvascular endothelial cells and human umbilical vein endothelial cells (HUVEC) is also inhibited by $\beta$-eudesmol. ${ }^{21)}$ It inhibits HUVEC migration stimulated by basic fibroblast growth factor and tube 
Table 2. Effect of $\beta$-Eudesmol and Three Channel Blockers on Acetylcholine-activated Channel Currents in Single Muscle Cells of Adult Mice

\begin{tabular}{lrll}
\hline \hline & & $\begin{array}{c}\text { Mean open time } \\
(\mathrm{msec})\end{array}$ & $\begin{array}{c}\text { Opening frequency } \\
(\mathrm{Hz})\end{array}$ \\
\hline Control & & $1.23 \pm 0.04(10)$ & $5.22 \pm 0.61(17)$ \\
Bupivacaine & 3 & $1.24 \pm 0.05(8)$ & $5.33 \pm 0.53(12)$ \\
$\quad(\mu \mathrm{M})$ & 10 & $1.05 \pm 0.04^{* *}(9)$ & $5.17 \pm 0.52(13)$ \\
& 30 & $0.87 \pm 0.03^{* *}(9)$ & $4.77 \pm 0.72(16)$ \\
& 100 & $\mathrm{~N} . \mathrm{D}$. & $0.35 \pm 0.17^{* *}(7)$ \\
Chlorpromazine & 3 & $1.25 \pm 0.04(7)$ & $4.19 \pm 0.64(14)$ \\
$(\mu \mathrm{M})$ & 10 & $1.22 \pm 0.04(5)$ & $1.17 \pm 0.21^{* *}(15)$ \\
& 30 & $\mathrm{~N} . \mathrm{D}$. & $0.12 \pm 0.04^{* *}(7)$ \\
Phencyclidine & 3 & $1.26 \pm 0.05(11)$ & $5.35 \pm 0.43(16)$ \\
$(\mu \mathrm{M})$ & 10 & $1.10 \pm 0.03^{*}(8)$ & $3.36 \pm 0.37^{*}(14)$ \\
& 30 & $0.97 \pm 0.04^{* *}(9)$ & $2.43 \pm 0.39^{* *}(16)$ \\
& 100 & $\mathrm{~N} . \mathrm{D}$. & $0.22 \pm 0.06^{* *}(6)$ \\
$\beta$-Eudesmol & 20 & $1.14 \pm 0.03(10)$ & $5.10 \pm 0.66(12)$ \\
$(\mu \mathrm{M})$ & 40 & $0.90 \pm 0.04^{* *}(7)$ & $2.68 \pm 0.37^{* *}(18)$ \\
& 80 & $0.74 \pm 0.08^{* *}(4)$ & $1.55 \pm 0.33^{* *}(15)$ \\
\hline
\end{tabular}

Acetylcholine $(1 \mu \mathrm{M})$-activated single channel currents were recorded from endplates of single muscle cells. Mean open time and opening frequency were estimated at a resting membrane potential. Each value is the mean \pm S.E.M. for the number of cells in parentheses. N.D. : not determined. ${ }^{*} p<0.05 ;{ }^{* *} p<0.01$, compared with the control value by $t$-test. (Reprinted from Kimura et al., 1991, with permission from Elsevier). ${ }^{17}$ )

Table 3. Effects of $\beta$-Eudesmol and Hydrocortisone on Angiogenesis in Adjuvant-induced Granuloma in Mice

\begin{tabular}{lcclc}
\hline \hline \multicolumn{1}{c}{ Drug } & $\begin{array}{c}\text { Dose } \\
(\mu \mathrm{mol} / \mathrm{kg})\end{array}$ & $n$ & $\begin{array}{c}\text { Carmine content } \\
(\mathrm{mg})\end{array}$ & $\begin{array}{c}\text { Inhibition } \\
(\%)\end{array}$ \\
\hline Control & 0 & 4 & $0.399 \pm 0.020$ & \\
Hydrocortisone & 9.3 & 4 & $0.264 \pm 0.023^{a)}$ & 33.8 \\
& 18.5 & 4 & $0.164 \pm 0.028^{a)}$ & 58.9 \\
Control & 0 & 3 & $0.366 \pm 0.027$ & \\
$\beta$-Eudesmol & 0.45 & 3 & $0.297 \pm 0.035$ & 18.9 \\
& 0.90 & 3 & $0.200 \pm 0.028^{a)}$ & 45.4 \\
\hline
\end{tabular}

The carmine content is an index of newly formed blood vessels in pouch granuloma. Data are means \pm S.E.M. $n=$ number of data. The extent of inhibition is expressed as a percentage of the carmine content in each control. a) $p<0.01$ vs. control. (Reprinted from Tsuneki et al., 2005, with permission from Elsevier), ${ }^{21)}$

formation of HUVEC in Matrigel. $\beta$-Eudesmol inhibits the angiogenesis in subcutaneously implanted Matrigel plugs in mice, the extent of which is much higher than that of thalidomide (Fig. 2(B)) .21) The blockade of extracellular signal-related kinase $1 / 2$ by $\beta$-eudesmol may be the common mechanism for its antiangiogenic action.

Therefore, $\beta$-eudesmol exhibits the following multiple pharmacological actions: 1) desensitization (channel blocking action) of nAChR, 2) antiangio-

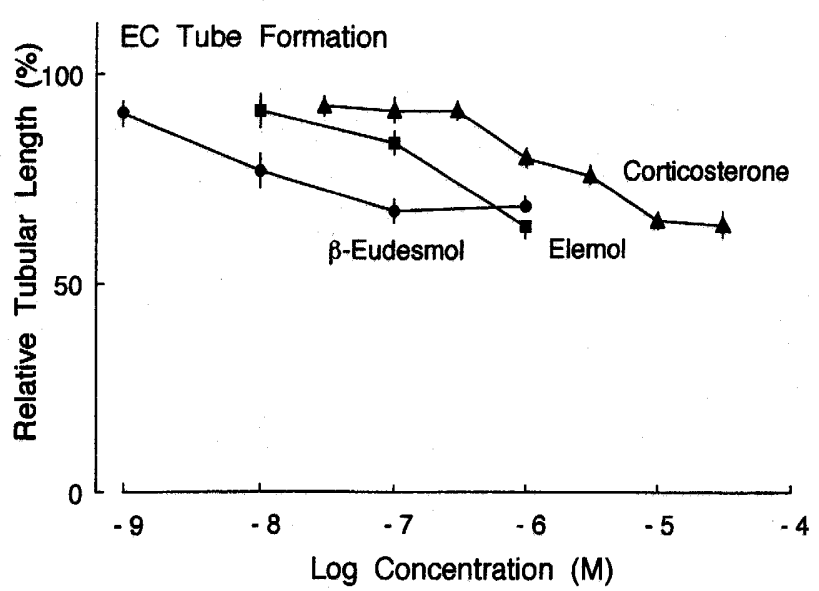

Fig. 2(A). Inhibitory Effect on Tube Formation of $\beta$-Eudesmol ( ), Elemol ( $\boldsymbol{\square}$ ) and Corticosterone ( $\boldsymbol{\Delta}$ ) (Unpublished Data)

Vascular endothelial cells derived from male Wistar rats were incubated with these compounds for 4 days. The values of \% relative tubular length of cells incubated with the compounds with respect to the values of those without the compounds and corticosterone are expressed as mean \pm S.E.M. of four analyses using three dishes.

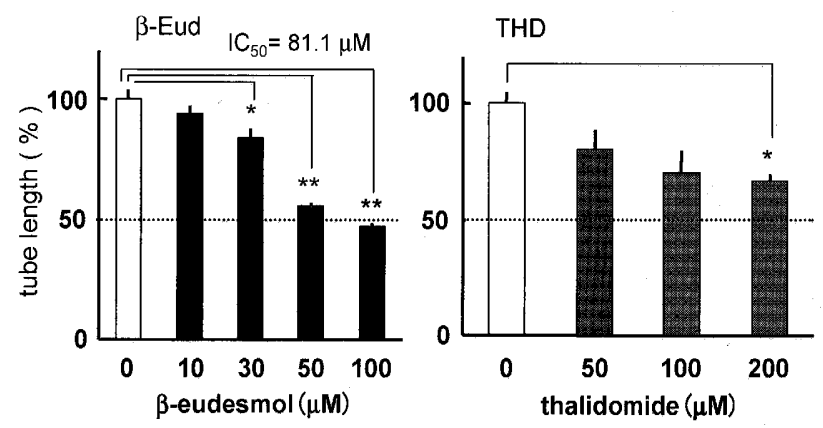

Fig. 2(B). Inhibitory Effect of $\beta$-Eudesmol and Thalidomide on Tube Formation of Human Umbilical Vein Endothelial Cells (HUVECs) in Matrigel ${ }^{21}$ )

Total tube length was measured on a digitized photograph as pixel length, and each value was normalized to the mean total tube length in the vehicle control and then averaged. Data are expressed as mean \pm S.E.M., $n=$ $4-6$ per group. ${ }^{*} p<0.05$ and ${ }^{* *} p<0.01$ vs each vehicle control. (Reprinted from Tsuneki et al., 2005, with permission from Elsevier). ${ }^{21)}$

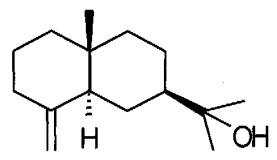

$\beta$-eudesmol

\section{(1) n-AChR channel blocker}

(2) Antiangiogenic activity more potent than hydrocortisone (3) Neurite outgrowth

Fig. 2(C). Chemical Structure and Summary of Multiactions of $\beta$-Eudesmol

genic actions in the vascular endothelium, and 3) neuronal differentiation induction (Fig. 2(C)). ${ }^{22)}$. The antiangiogenic actions may be favorable for treating angiogenic diseases including diabetic complications 


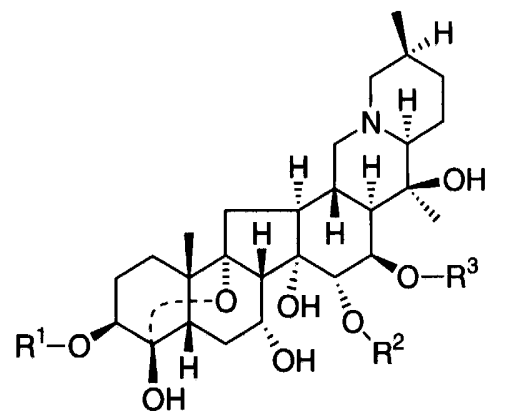

\begin{tabular}{llccc} 
& & $\mathrm{R}^{1}$ & $\mathrm{R}^{2}$ & $\mathrm{R}^{3}$ \\
\hline \hline $\mathbf{U}_{7}$ & Germidine & $\mathrm{Ac}$ & $\mathrm{MB}$ & $\mathrm{H}$ \\
$\mathbf{U}_{9}$ & Germerine & $\mathrm{HMB}$ & $\mathrm{MB}$ & $\mathrm{H}$ \\
$\mathbf{U}_{10}$ & $\begin{array}{l}\text { 15-O-(2-methyl- } \\
\text { butyroyl) }\end{array}$ & $\mathrm{H}$ & $\mathrm{MB}$ & $\mathrm{H}$ \\
$\mathbf{U}_{11}$ & Verussurinine & $\mathrm{H}$ & $\mathrm{H}$ & $\mathrm{MB}$ \\
$\mathbf{U}_{12}$ & Neogermbudine & $\mathrm{HMB}$ & $\mathrm{MB}$ & $\mathrm{H}$ \\
\hline
\end{tabular}

$\mathrm{Ac}=$ Acetyl, $\mathrm{MB}=2$-Methylbutyroyl, $\mathrm{HMB}=2$-Hydroxy-2-methylbutyroyl

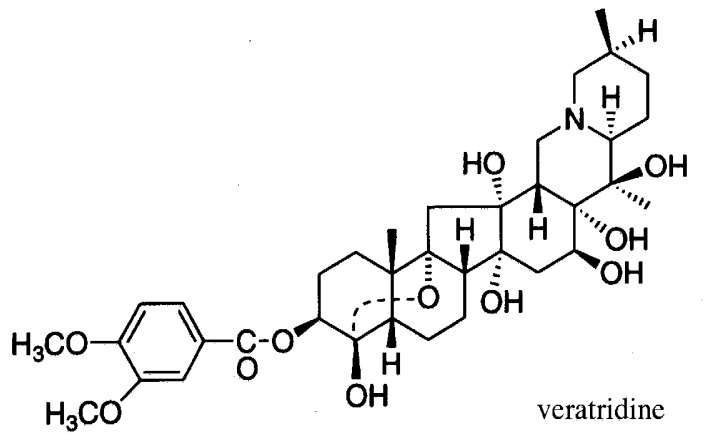

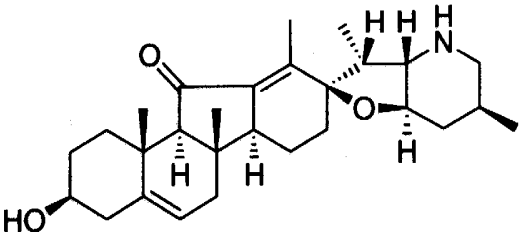

$\mathrm{U}_{8}$ jervine

Fig. 3(A). Chemical Structures of Steroidal Alkaloids Derived from V. nigrum var. ussriense and Varatiridine (Reprinted from Kimura et al., 2000, with permission from JANPR). ${ }^{24)}$

Germidine ( $\mu \mathrm{g} / \mathrm{kg}$, i.p.)
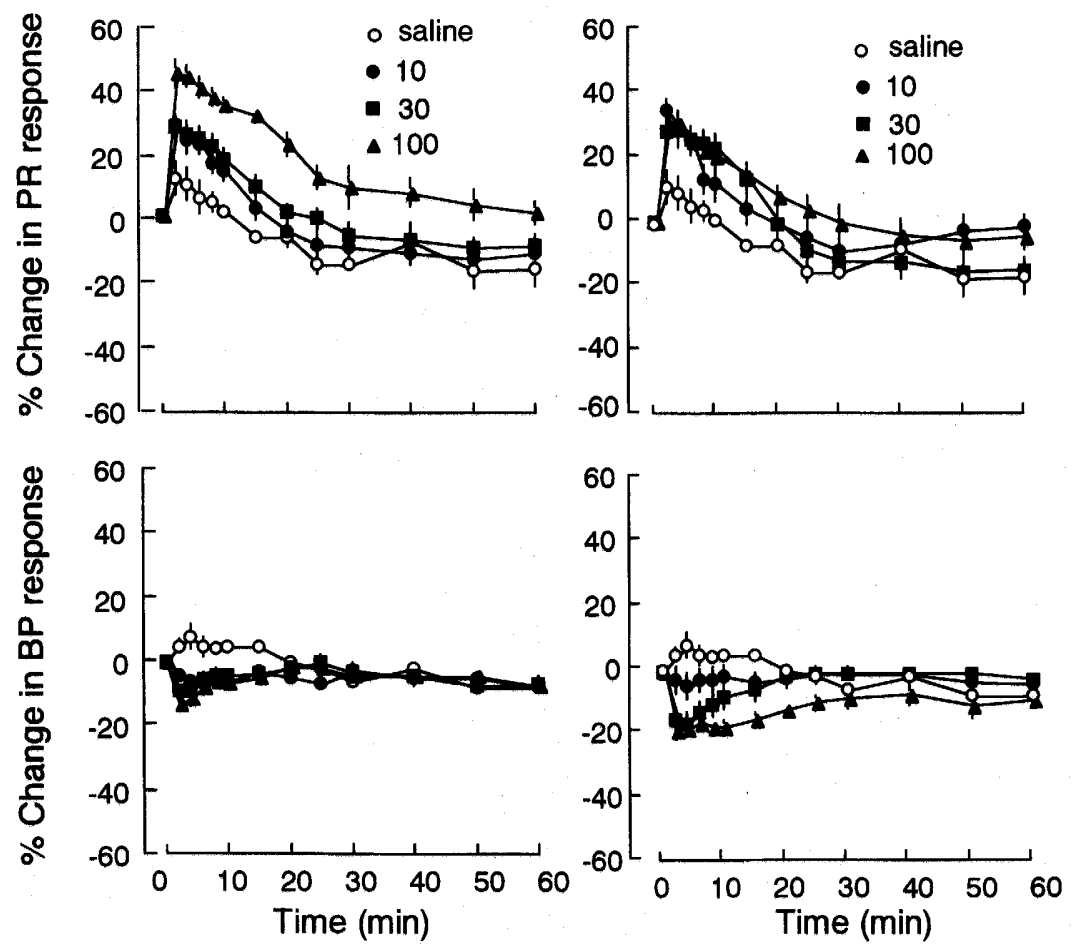

Fig. 3(B). Time-dependent Increases in Pulse Rates (PR, Upper Panel) and Blood Pressure (BP) Lowering Effect (Lower Panel) of Germidine (Left) and Germerine (Right) in Conscious Mice ${ }^{24)}$

Germidine $(\mathbf{O}: 10, \mathbf{\square}: 30, \mathbf{\Delta}: 100 \mu \mathrm{g} / \mathrm{kg})$, germerine $(\mathbf{O}: 10, \boldsymbol{\square}: 30, \mathbf{\Delta}: 100 \mu \mathrm{g} / \mathrm{kg}$ ) and saline $(\mathrm{O})$ were administered $i . p$. in conscious mice. The PR and BP responses were estimated as percentage changes in the values of PR and BP before the administration of crude drugs, respectively. All values are expressed as mean \pm S.E.M. $(n=7)$. (Reprinted from Kimura et al., 2000, with permission from JANPR) ${ }^{24)}$ 


\section{veratrum alkaloids}
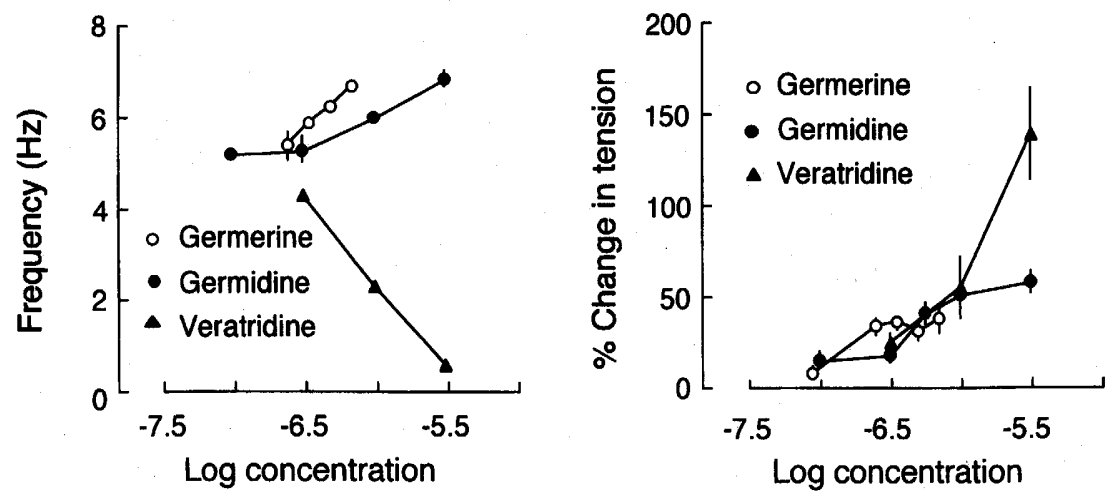

Fig. 3(C). Log Concentration-response Curves of Chronotropic (Upper) and Inotropic (Lower) Effects of Germidine (O), Germerine $(\mathrm{O})$ and Veratridine $(\mathbf{A})$ in Isolated Atrial Preparations of Mice

The spontaneous beating rate (frequency, $\mathrm{Hz}$ ) and the percentage changes in the values of contraction force before the administration of Veraturum alkaloids were measured in isolated right atria and in the left atria electrically stimulated at $4 \mathrm{~Hz}$, respectively. All values are expressed as mean \pm S.E.M. ( $n=5$ ). (Reprinted from Kimura et al., 2000, with permission from JANPR) . ${ }^{24)}$

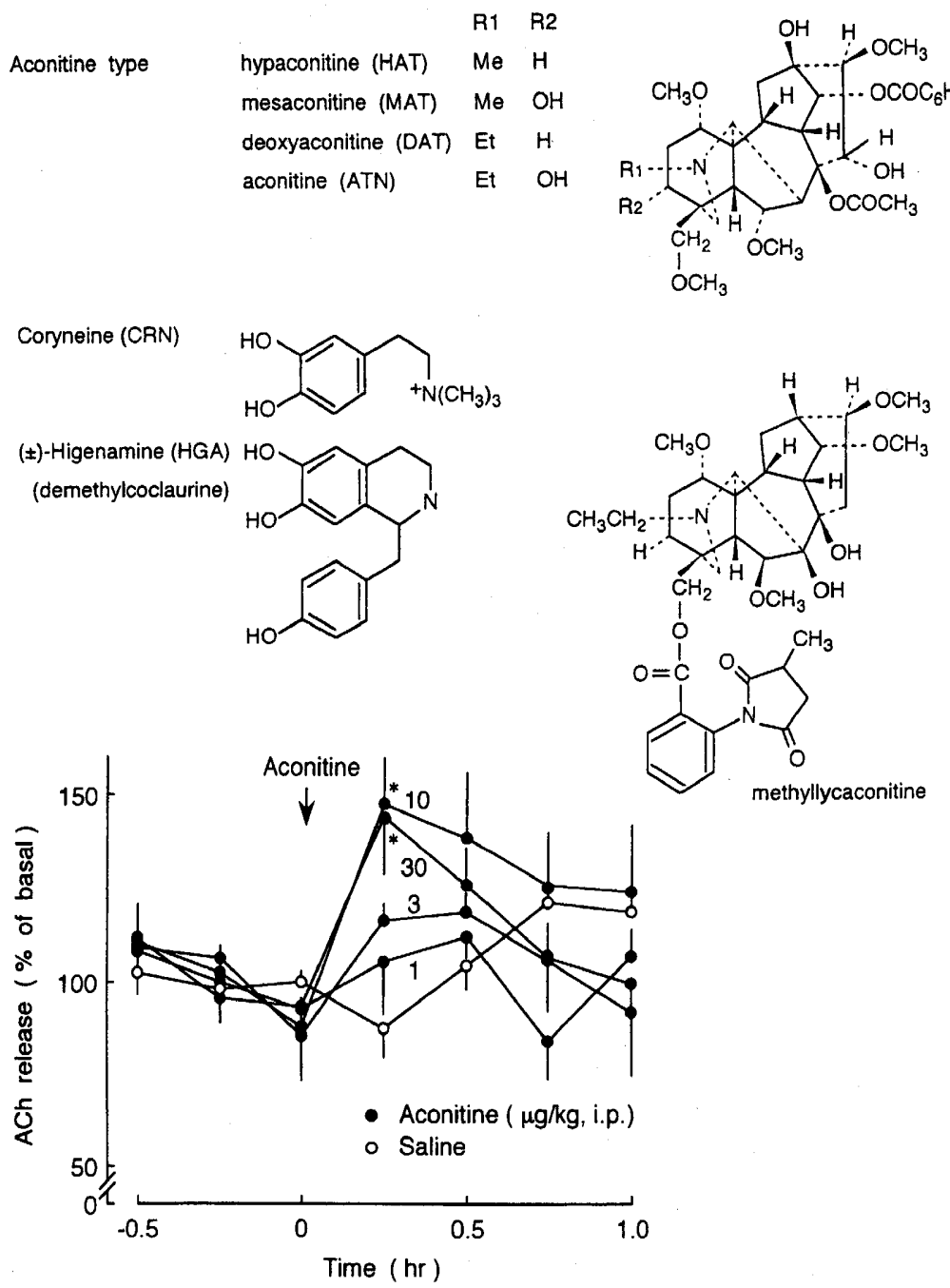

Fig. 4(A). Main Constituent Compounds of Aconite Root, Its Related Compound Methyllycaconitine, and Acetylcholine (ACh) Release from Frontal Cerebral Cortex of Rat Peripherally Administered with Aconitine

(Reprinted from Kimura et al., 1996, with permission from the Pharmaceutical Society of Japan). ${ }^{29)}$ 
and possibly cancer.

\section{BLOOD PRESSURE LOWERING EFFECT OF STEROIDAL VERATRUM ALKALOIDES WITHOUT VERATRIDINE-LIKE MECHANISMS}

Crude alkaloids isolated from Veratrum (viride, $V$. grandiflorum, $V$. oxysepalum and $V$. stamineum (Liliaceae) have been shown to continuously lower blood pressure markedly in wild dogs. ${ }^{23)}$ Crude alkaloids from $V$. nigrum var. ussuriense, and $V$. mackii, and their constituents, namely, germidine and germerine, lower blood pressure and increase pulse rate in conscious mice. ${ }^{24)}$ Veratridine, a steroidal alkaloid constituent derived from $V$. album, activates the $\mathrm{Na}^{+}$channel by blocking its inactivation, followed by the prolongation of the opening of the chan-

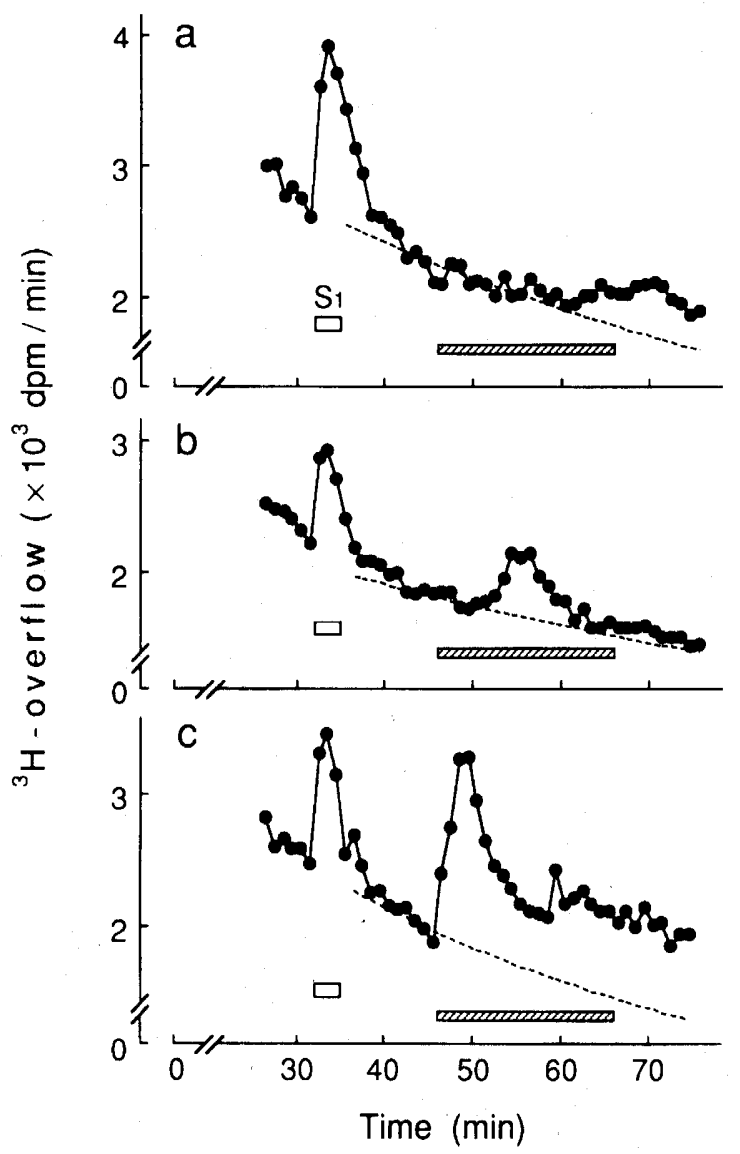

Fig. 4(B). Effects of Aconitine on Spontaneous Release of Tritium Radioactivity $\left({ }^{3} \mathrm{H}\right.$-Choline and ${ }^{3} \mathrm{H}$-Acetylcholine) from Mouse Phrenic Nerve-hemidiaphragm Preparation ${ }^{31)}$

The nerve was stimulated $(50 \mathrm{~Hz}$, trains of 40 stimuli at intervals of 10 sec) for $3 \mathrm{~min}$ as indicated by the open column. The shaded column indicates the presence of aconitine (a: $1 \mu \mathrm{M}, \mathrm{b}: 3 \mu \mathrm{M}, \mathrm{c}: 30 \mu \mathrm{M}$ ). Each point represents the mean tritium radioactivity $(n=3-4)$. The dotted line indicates the mean of expected outflows calculated from the control outflows without aconitine. The horizontal axis indicates the time after the end of the washout period. (Reprinted from Okazaki et al., 1994, with permission from the Japanese Pharmacological Society) . ${ }^{31)}$. nel and its action potential, and augments cardiac contractions. The alkaloid also alters the gating and permeability properties of $\mathrm{Na}^{+}$current. ${ }^{25)}$ Germerine and germidine (Fig. 3(A)) decrease blood pressure accompanied by positive chronotropy (Figs. 3(B), (C)), whereas veratridine (Fig. 3(A)) decreases blood pressure accompanied by negative chronotropy (Fig. 3(C)). Therefore, germerine analogues are more favorable candidates as antihypertensive drugs than veratridine.

\section{CENTRAL MUSCARINIC CARDIOTONIC ACTIONS OF ACONITINE}

Processed aconite roots that contain small amounts of aconitine, which is regarded only as a neurotoxin by Western scientists, have continued to be clinically
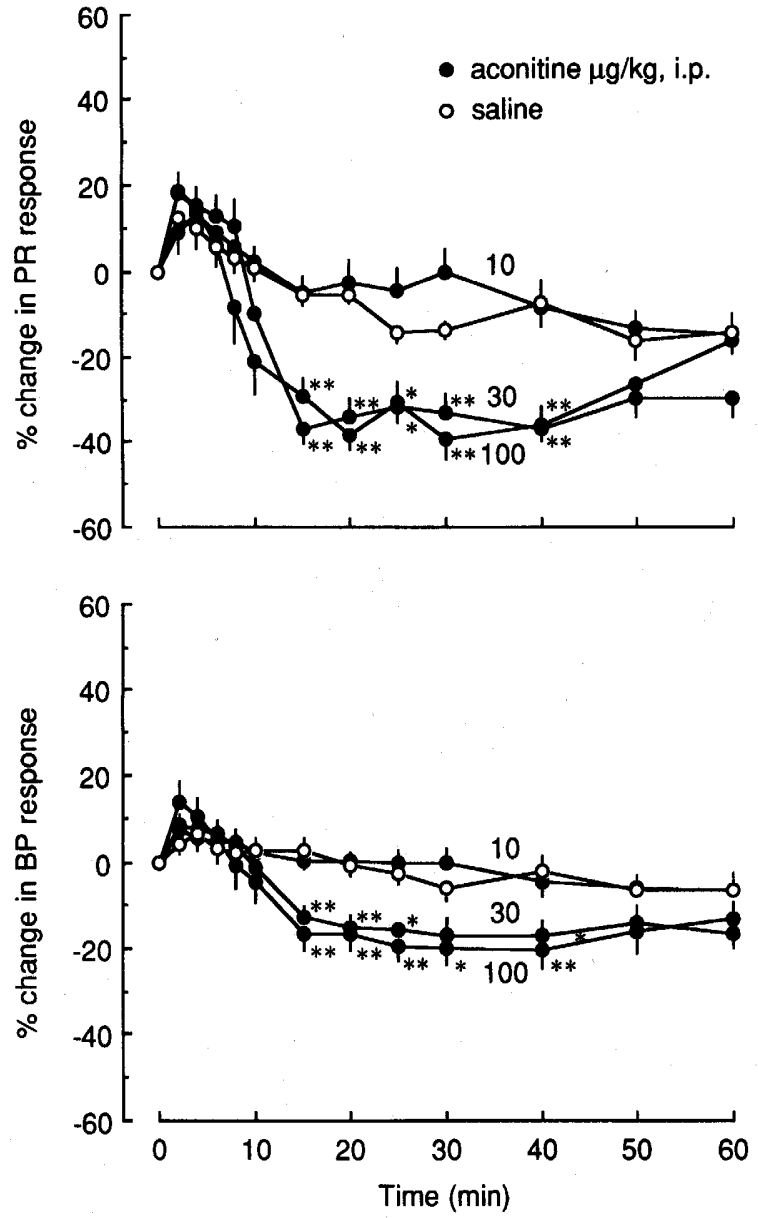

Fig. $4(\mathrm{C})$. Bradycardia and Blood Pressure Lowering Effects of Aconitine ${ }^{32)}$

Time-course changes in pulse rate (upper) and blood pressure (lower) after administration of aconitine $(10,30$ and $100 \mu \mathrm{g} / \mathrm{kg}, i . p$. $)$ to unanaesthetized ddY mice. Each value represents the mean \pm S.E.M. of $6-12$ experiments. $\bigcirc$ : saline control, $O$ : aconitine. ${ }^{*} p<0.05$ and ${ }^{* *} p<0.01$ : significantly different from saline control as determined by ANOVA and multiple range test of Tukey. (Reprinted from Kimura et al., 1994, with permission from John Wiley \& Sons Limited) . ${ }^{32)}$ 


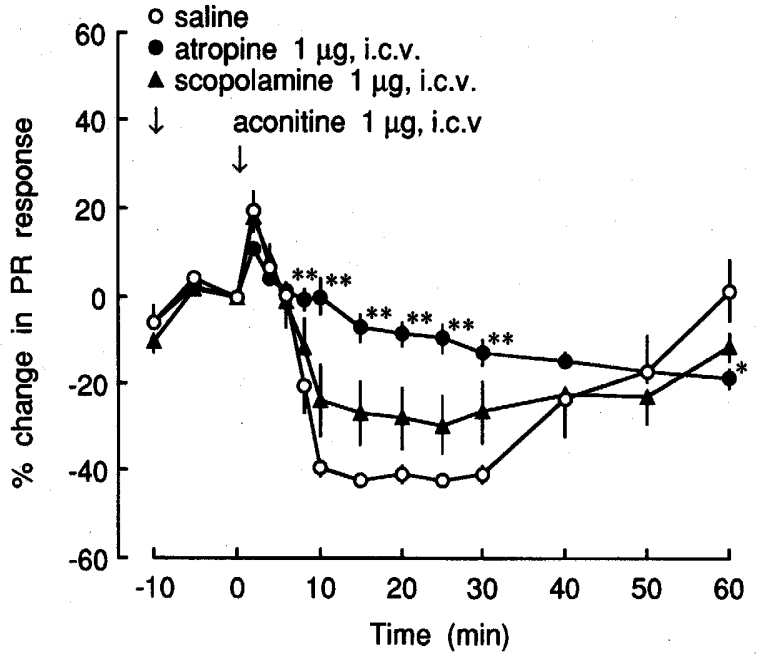

Fig. 4(D) . Effects of Centrally Applied Aconitine and Muscarinic Antagonists on Aconitine $(1 \mu \mathrm{g}, i . c . v$.$) -induced$ Pulse Rate Response

Time-course changes after administration of saline, atropine and scopolamine $10 \mathrm{~min}$ before aconitine treatment. Each value represents the mean \pm S.E.M. of 10 experiments. Bradycardia was prevented in all mice (10 10) by atropine, and in $5 / 10$ mice by scopolamine. Significant differences $\left({ }^{*} p<0.05\right.$ and $\left.{ }^{* *} p<0.01\right)$ from the saline-treated group were determined using multiple range test of Tukey. (Reprinted from Kimura et al., 1994, with permission from John Wiley \& Sons Limited) ${ }^{32)}$

used in China and Japan for many years because of their therapeutic value. Their toxicities are minimized to a tolerable level during processing. Aconitine has a wide range of pharmacological actions at very low concentrations. Processed aconite roots have frequently been used in Kampo medicines to partially relieve muscle pain due to their neuromuscular blocking actions, ${ }^{13,26)}$ and as cardiotonic and anti-inflammatory agents. ${ }^{27)}$ All of these actions may be due to the induction of the opening of voltage-sensitive $\mathrm{Na}^{+}$ channels in various cell types. ${ }^{28)}$ Aconitine increases spontaneous ACh release from the frontal cerebral cortex ${ }^{29,30)}$ and from the motor nerves through the prolonged activation of $\mathrm{Na}^{+}$channels (Figs. 4(A), (B)). ${ }^{31)}$ When administered peripherally, aconitine induces bradycardia (Fig. 4(C)), probably through a pathway involving the anterior hypothalamus in conscious mice (Fig. 4(D)) . ${ }^{32,33)}$ Aconitine is equipotent to hydrocortisone and indomethacin in inhibiting angiogenesis, ${ }^{27)}$ and it stimulates the response to interferon- $\gamma$-activated expression of major histocompatibility complex class II antigen by macrophages in mice. ${ }^{34)}$

\section{ANTIGLAUCOMA ACTIONS OF NIPRADILOL}

Nipradilol (3,4-dihydro-8-(2-hydroxy-3-isopropyl-

\section{Antiglaucoma drugs}

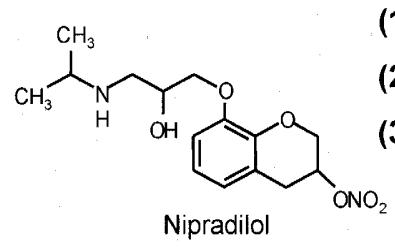

(1) $\beta$-adrenergic blocker

(2) $\alpha_{1}$-adrenergic blocker

(3) NO donor

COX activation endogenous PGs production

Fig. 5(A). Chemical Structure and Summary of Multiactions of Nipradilo1 ${ }^{40)}$

a

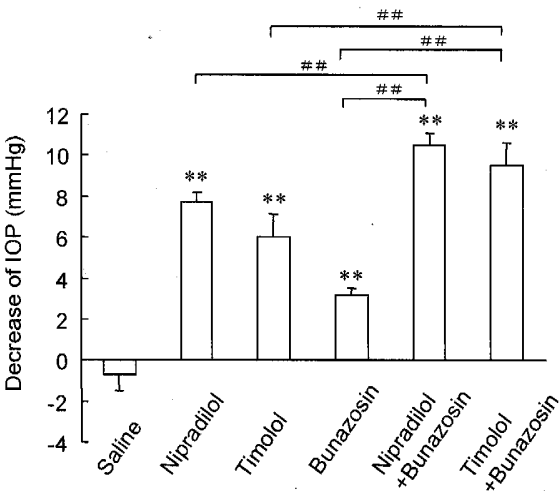

b

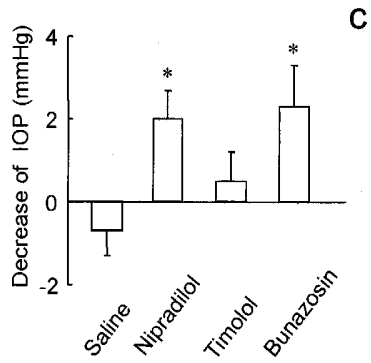

C

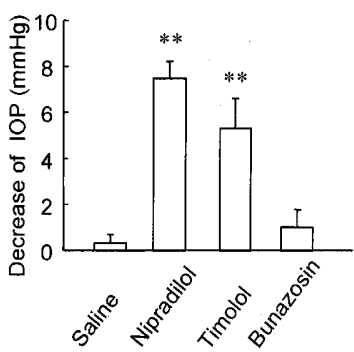

Fig. 5(B). Multiple Effects of Nipradilol on Intraocular Pressure (IOP) in Rabbits

a) Effects of nipradilol, timolol, bunazosin, and their combinations (nipradilol + bunazosine, and timolol + bunazosine) on ocular normotensive rabbits. For the combined treatment, nipradilol or timolol was instilled $5 \mathrm{~min}$ before bunazosin instillation. IOP was measured $60 \mathrm{~min}$ after drug instillation. As for the control, saline was used. b) Additive effects of nipradilol, timolol, and bunazosin on ocular normotensive rabbits $60 \mathrm{~min}$ after $5 \%$ timolol instillation, under conditions saturated with adrenergic $\beta$-blocking activity. IOP was measured before $5 \%$ timolol application $(-60 \mathrm{~min})$, and 0 $\mathrm{min}$ and $60 \mathrm{~min}$ after drug instillation. As for the control, saline was in stilled. c) Additive effects of nipradilol and timolol on ocular normotensive rabbits $60 \mathrm{~min}$ after $0.1 \%$ bunazosine instillation, under conditions saturated with $\alpha_{1}$-blocking activity. IOP was measured before $0.1 \%$ bunazosine application $(-60 \mathrm{~min})$ and $0 \mathrm{~min}$ and $60 \mathrm{~min}$ after drug instillation. As for the control, saline was instilled. Data represent the decrease in IOP from the value at $0 \mathrm{~min}$ and are expressed as the mean \pm S.E.M. of six rabbits. (Dunnett's multiple range test; ${ }^{*} p<0.05,{ }^{* *} p<0.01$ vs IOP decrease in saline control. ${ }^{\#} p<0.01$ ). (Reprinted from Orihashi et al., 2005, with permission from the Japanese Ophthalmological Society). ${ }^{40)}$

amino) propoxy-3-nitroxy-2H-1-benzopyran) is clinically utilized as a topical antiglaucoma drug. Initially, nipradilol was synthesized as an antihypertensive agent having $\beta$-adrenoceptor blocking actions, ${ }^{35)}$ and 


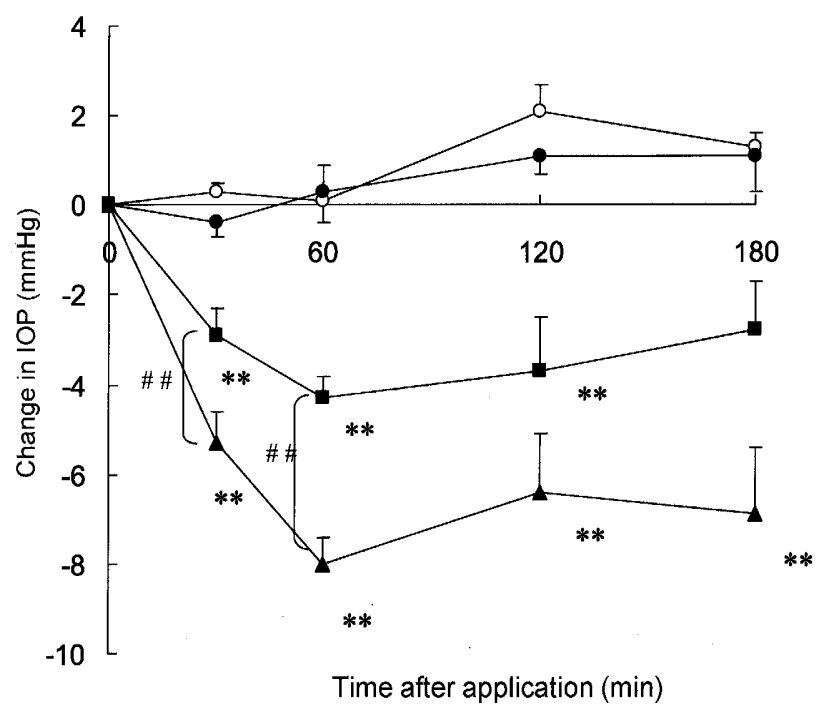

Fig. 5(C). IOP Changes after Instillation of Nipradilol with Pretreatment of c-PTIO, an NO Trap

In the combined treatment study, saline or c-PTIO was instilled $5 \mathrm{~min}$ before nipradilol instillation. As for the control, saline was instilled. Data represent the changes in IOP of rabbits treated with saline $(O)$, c-PTIO $(\boldsymbol{O})$, saline + nipradilol $(\boldsymbol{\Lambda})$, c-PTIO + nipradilol $(\mathbf{\square})$, and are expressed as mean \pm S.E.M. of four or seven rabbits. (Dunnett's multiple range tests; ${ }^{* *} p$ $<0.01$ vs 0 min value after drug instillation. ${ }^{*} p<0.05,{ }^{*} p<0.01$ ). (Reprinted from Orihashi et al., 2005, with permission from the Japanese Ophthalmological Society) ${ }^{40)}$

then as a nonselective $\alpha_{1}$ blocking agent. ${ }^{36-38)}$ The ocular hypotensive effects of the compound are caused by increased ocular blood flow due to its nonselective $\alpha_{1}$-blocking actions, $\beta$-adrenergic blocking actions, and nitric oxide (NO) production through its denitrification (Figs. 5(A), (B), (C) ). ${ }^{39,40)}$ Nipradilol has also been shown to dilate canine retinal artery and arteriole, ${ }^{41)}$ and substantially increase uveoscleral outflow. ${ }^{42)}$ The topical application of nipradilol suppresses the endothelin-1-induced contraction of the retinal artery, ${ }^{43)}$ and lowers intraocular pressure in ocular hypertensive rabbits. ${ }^{44)}$ All these effects are considered to contribute to the clinical antiglaucoma actions of nipradilol.

\section{DISCUSSION}

In this review, we have demonstrated the multiple pharmacological actions of gimnemic acid IV as an antihyperglycemic agent, $\beta$-eudesmol as an antiangiogenic agent, germerine as an antihypertensive agent, aconitine as an activator for the release of endogenous bioactive substances, and nipradilol as an antiglaucoma drug.

Salicin, found in many species of willow (Salix species; Salicaceae) inactivates cyclooxygenase-2, and is responsible for the analgesic and antipyretic effects of<smiles>COc1ccccc1C(=O)O</smiles>

Aspirin
Anti-inflammation

Anti-pyretic analgesic

Anti-platelet

Prophylactic effects of aspirin

- Myocardial infarction

- Angina - stroke · cancer

- Alzheimer's disease

Fig. 6. Chemical Structure and Summary of Multiple Pharmacological Actions of Aspirin

willow barks. Salicin also serves as the template for the synthesis of aspirin which is a more effective analogue. Aspirin, a traditional nonsteroidal anti-inflammatory drug, that inhibits both cyclooxygenase- 1 and -2 is re-evaluated and classified as a powerful drug having multiactions for the prophylactic treatments of cardiac infarction, angina pectoris, stroke, and dementia (Fig. 6). Patients undergoing coronary angioplasty are given aspirin because it reduces thromboxane $A_{2}$ production and platelet clumping and hence, the possibility of myocardial infarction. ${ }^{45}$ ) Aspirin also triggers the generation of lipoxin, which partially counteracts the adverse effects of prostaglandin suppression. ${ }^{46)}$ Its anti-inflammatory and antiplatelet effects may be due to its multiple pharmacological actions.

A single crude drug in traditional medicine frequently contains yin-yang components that have mutually opposing pharmacological activities beneficial for the targeted disease. The higher potency of the crude drug is brought about by the synergistic effect among its component compounds, even though the potency of each compound is weak when used alone. This is one reason why Kampo formulation is composed of several crude drugs. ${ }^{47)}$ However, a single pure compound by itself has multiple pharmacological actions similarly to a single crude drug. Their actions may likely be linked to common proteins in physiological or pathological circuits. Genome sciences, combined with bioinformatic tools, also allow us to dissect the genetic basis of multifactorial diseases and to determine the most suitable areas for intervention for future therapies, thereby increasing the number of treatment options. ${ }^{48)}$ If all multiple pharmacological actions are efficiently combined in 
one compound to cure chronic diseases exhibiting various symptoms without harmful side effects, this compound will be considered as a highly efficacious drug due to its pleiotropic actions.

\section{CONCLUSION AND PERSPECTIVES}

It is well recognized that the selectivity and specificity of drug action are required for effectively treating acute diseases, infections or for acting as useful reagents. The nosological entities in lifestyle-related diseases can be classified as multifactorial diseases. For chronic multifactorial diseases, the pleiotropic actions of gimnemic acid IV, $\beta$-eudesmol, nipradilol and aspirin may still continue to be effectively and therapeutically exploited in the future. The present lines of evidence suggest that pleiotropic actions are important in developing new drugs for chronic diseases presenting various symptoms.

Acknowledgments We thank Dr. Hiroshi Tsuneki (University of Toyama, Department of Clinical Pharmacology, Toyama 930-0194, Japan) for editing the manuscript, Drs. Takahito Kimura and Masahiro Orihashi (Teika Pharmaceutical Co., Ltd., Toyama 930-0982, Japan) for their constructive comments on the nipradilol effects in this manuscript, and Dr. Shinjiro Kobayashi (Hokuriku University, Department of Clinical Pharmacology, Kanazawa 920-1181, Japan) for unpublished data on the antiangiogenic effects of $\beta$-eudesmol on rat aortic endothelial cells.

\section{REFERENCES}

1) Kimura M., Suzuki J., Waki I., Kimura I., Tanaka O., Matsuura H., Proc. 4th Inter. Ginseng Symp., 1984, pp. 191-197.

2) Kimura M., Waki I., Tanaka O., Nagai Y. Shibata S., J. Pharmacobiodyn., 4, 402-409 (1981).

3) Chen F., Nakashima N., Kimura I., Kimura M., Asano N., Koya S., Biol. Pharm. Bull., 18, 1676-1680 (1995).

4) Kimura M., Chen F., Nakashima N., Kimura I., Asano N., Koya S., J. Trad. Med., 12, 214219 (1995).

5) Nojima H., Kimura I., Chen F.-J., Sugihara Y., Haruno M., J. Nat. Prod., 61, 397-400 (1998).

6) Sugihara Y., Nojima H., Matsuda H., Murakami T., Yoshikawa M., Kimura I., $J$.
Asian Nat. Prod. Res., 2, 321-327 (2000).

7) Yoshikawa M., Murakami T., Matsuda H., Chem. Pharm. Bull., 45, 2034-2038 (1997).

8) Yoshikawa K., Amimoto K., Arihara S., Matsuura K., Tetrahedron Lett., 30, 1103-1106 (1989).

9) Nakashima N., Kimura I., Kimura M., J. Nat. Prod., 56, 345-350 (1993).

10) Tsuneki H., Ishizuka M., Terasawa M., Wu J.-B., Sasaoka T., Kimura I., BMC Pharmacol., 4, 18 (2004).

11) Kimura I., Nojima H., Kimura M., "Studies in Natural Products Chemistry, Vol. 24," ed. by Atta-ur-Rahman, 2000, pp. 875-932.

12) Kimura I., Nakashima N., Sugihara Y., Chen F.-J., Kimura M., Phytother. Res., 13, 484488 (1999).

13) Kimura M., Kimura I., Muroi M., Yoshizaki M., Hikino H., Phytother. Res., 1, 107-113 (1987).

14) Muroi M., Tanaka K., Kimura I., Kimura M., Jpn. J. Pharmacol., 50, 69-71 (1989) .

15) Nojima H., Kimura I., Kimura M., Brain Res., 575, 337-340 (1992).

16) Muroi M., Kimura I., Kimura M., Neuropharmacology, 29, 567-572 (1990).

17) Kimura M., Nojima H., Muroi M., Kimura I., Neuropharmacology, 30, 835-841 (1991) .

18) Kimura I., Tsuneki H., Kondoh T., Kimura M., J. Pharmacol. Exp. Ther., 256, 24-28 (1991).

19) Kimura M., Kimura I., Kondoh T., Tsuneki H., J. Pharmacol. Exp. Ther., 256, 18-23 (1991).

20) Kimura M., Kimura I., Luo B., Kobayashi S., Phytother. Res., 5, 195-200 (1991).

21) Tsuneki H., Ma E.-L., Kobayashi S., Sekizaki N., Maekawa K., Sasaoka T., Wang M.-W., Kimura I., Eur. J. Pharmacol., 512, 105-115 (2005).

22) Obara Y., Aoki T., Kusano M., Ohizumi Y., J. Pharmacol. Exp. Ther., 301, 803-811 (2002).

23) Kimura I., Islam Md. A., Nojima H., Mizumoto J., Tezuka Y., Weijie Z., J. Trad. Med., 15, 254-255 (1998).

24) Kimura I., Islam Md. A., Honda R., Nojima H., Tezuka Y., Zhao W., J. Asian Nat. Prod. Res., 2, 133-144 (2000). 
25) Cole W. C., Chartier D., Martin F., Leblanc N., Am. J. Physiol., 42, H128-H137 (1997).

26) Kimura M., Muroi M., Kimura I., Sakai S., Kitagawa I., Jpn. J. Pharmacol., 48, 290-293 (1988).

27) Luo B., Kobayashi S., Kimura I., Kimura M., Phytother. Res., 5, 231-233 (1991).

28) Caterall W. A., Ann. Rev. Pharmacol. Toxicol., 20, 15-43 (1980).

29) Kimura I., Takada M., Nojima H., Kimura M., Biol. Pharm. Bull., 19, 1440-1442 (1996).

30) Kimura I., Kimura M., "Pharmacology and Therapeutics in the New Millennium," ed. by Gupta S. K., 2001, pp. 336-344.

31) Okazaki M., Kimura I., Kimura M., Jpn. J. Pharmacol., 66, 421-426 (1994).

32) Kimura I., Makino M., Matsui T., Takada M., Kimura M., Phytother. Res., 8, 129-134 (1994) .

33) Kimura I., Takada M., Nojima H., Biol. Pharm. Bull., 20, 856-860 (1997).

34) Kimura I., Makino M., Honda R., Ma J., Kimura M., Biol. Pharm. Bull., 18, 15041508, (1995).

35) Uchida Y., Nakamura M., Shimizu S., Shirasawa Y., Fujii M., Arch. Int. Pharmacodyn. Ther., 262, 132-149 (1983).

36) Kinami J., Tsuchihashi H., Maruyama K., Sasaki K., Nagatomo T., Jpn. J. Pharmacol.,
61, 81-86 (1993)

37) Ohira A., Wada Y., Fujii M., Nakamura M., Kasuya Y., Hamada Y., Shigenobu K., Arch. Int. Pharmacodyn. Ther., 278, 61-71 (1985).

38) Nakagawa Y., Nakahara H., Chin W.-P., Imai S., Jpn. J. Pharmacol., 39, 481-485 (1985)

39) Yoshitomi T., Yamaji K., Ishikawa H., Ohnishi Y., Exp. Eye Res., 75, 669-676 (2002).

40) Orihashi M., Shima Y., Tsuneki H., Kimura I., Jpn. J. Ophthalmol., 49, 523-526 (2005) .

41) Okamura T., Kitamura Y., Uchiyama M., Toda M., Ayajiki K., Toda N., Pharmacology, 53, 302-310 (1996).

42) Kanno M., Araie M., Tomita K., Sawanobori K., Invest. Ophthalmol. Vis. Sci., 39, 736-743 (1998).

43) Mizuno K., Koide T., Yoshimura M., Araie M., Invest. Ophthalmol. Vis. Sci., 42, 688-694 (2001).

44) Orihashi M., Shima Y., Tsuneki H., Kimura I., Biol. Pharm. Bull., 28, 65-68 (2005).

45) Vane J. R., Science, 296, 474-475 (2002).

46) Wallace J. L., Fiorucci S., Trends Pharmacol. Sci., 24, 323-326 (2003).

47) Kimura I., Tsuneki H., J. Trad. Med., 22, 1-3 (2005) .

48) Drews J., Science, 287, 1960-1964 (2000). 